\title{
Configurações
}

Revista Ciências Sociais

\section{Sociologia na Academia Militar: de uma história improvável aos desafios atuais}

Sociology at the Military Academy: from an unlikely history to current challenges

La Sociologie à l'Académie militaire : d'une histoire improbable aux enjeux actuels

\section{ANA ROMÃO}

\section{OpenEdition}

\section{Journals}

Edição electrónica

URL: https://journals.openedition.org/configuracoes/13774

DOI: 10.4000/configuracoes. 13774

ISSN: 2182-7419

\section{Editora}

Centro de Investigação em Ciências Sociais

Edição impressa

Paginação: 11-26

ISSN: 1646-5075

\section{Refêrencia eletrónica}

ANA ROMÃO, «Sociologia na Academia Militar: de uma história improvável aos desafios atuais», Configurações [Online], 28 | 2021, posto online no dia 15 dezembro 2021, consultado o 28 dezembro 2021. URL: http://journals.openedition.org/configuracoes/13774 ; DOI: https://doi.org/10.4000/ configuracoes. 13774 
ROMÃo, Ana - Sociologia na Academia Militar: de uma história improvável aos desafios atuais.Configurações [em linha]. 28 (2021) p. 11-26.

\title{
Sociologia na Academia Militar: de uma história improvável aos desafios atuais
}

ANA ROMÃO*

Academia Militar, Centro de Investigação da Academia Militar (CINAMIL); Centro Interdisciplinar de Ciências Sociais (CICS.NOVA).

\begin{abstract}
Resumo
O artigo reflete sobre o lugar da Sociologia na formação académica de oficiais, tomando como principal referência a Academia Militar, instituição onde se formam os oficiais que ingressarão nos quadros do Exército e da Guarda Nacional Republicana. Caracteriza-se a presença da Sociologia no ensino universitário militar, faz-se um enquadramento histórico e compara-se tendências internacionais. Neste percurso, ressalta a grande diversidade de situações, bem como as resistências que foi necessário ultrapassar. Em Portugal, a incorporação de abordagens sociológicas na Academia Militar antecedeu a institucionalização universitária da Sociologia e foi mais precoce e bem aceite do que em países com antigas e fortes tradições sociológicas.
\end{abstract}

Palavras-chave: Sociologia, Ensino Universitário Militar, Formação de oficiais, Academia Militar.

\section{Abstract \\ Sociology at the Military Academy: from an unlikely history to current challenges}

The article focuses on the place of Sociology in the military officer's education, having as a reference the Portuguese Military Academy, the institution that qualifies the officers for the ranks of the Army and the National Republican Guard. We will present the position of Sociology in military university education from a historical perspective and in comparison with other countries. This journey highlights the great diversity of situations, as well as the resistance that had to be overcome. In Portugal, the incorporation of sociological approaches in military training preceded the university institutionalisation of sociology, which occurred earlier and was less controversial than in countries with older and strong sociological traditions.

*E-mail: anaromao74@gmail.com | ORCID ID: http://orcid.org/0000-0002-9791-5172 
Keywords: Sociology, Military University Education, Officer Training, Military Academy.

\section{Resumé}

La Sociologie à l'Académie militaire : d'une histoire improbable aux enjeux actuels

L'article réfléchit à la place de la Sociologie dans la formation académique des officiers, en prenant comme référence principale l'Académie militaire, l'institution qui forme les officiers de l'Armée et de la Gendarmerie. Nous présentons la situation de la Sociologie dans l'enseignement universitaire militaire du point de vue historique et en comparaison avec d'autres pays. Ce parcours met en évidence la diversité de situations, ainsi que les résistances qu'il a fallu surmonter. Au Portugal, l'incorporation des approches sociologiques dans la formation militaire a précédé l'institutionnalisation universitaire de la discipline et a été mieux acceptée que dans certains pays ayant des traditions sociologiques plus anciennes et plus fortes.

Mots-clés: Sociologie, enseignement universitaire militaire, formation des officiers, académie militaire.

\section{Introdução}

O presente artigo foi estimulado pela participação numa mesa-redonda organizada por ocasião do XI Congresso Português de Sociologia, em que se refletiu sobre o ensino da Sociologia e em que a nossa opção foi, tal como agora, tomar por objeto a Sociologia na formação académica dos oficiais. O pressuposto genérico é o de que a inclusão de saberes sociológicos em ciclos de estudos de outras áreas científicas valoriza a abertura transdisciplinar no sistema universitário, mas sobretudo tem potencialidades não negligenciáveis nas aprendizagens e na construção das visões do mundo das gerações que irão ter voz ativa em múltiplas áreas de atividade, quer enquanto profissionais, quer como cidadãos. Quando se trata da formação dos futuros oficiais, a questão torna-se mais interessante porque os oficiais são especialmente influentes nas dinâmicas de reprodução dos conhecimentos profissionais, na incorporação dos valores e da ética militar. Isto porque, nas academias militares, a formação para a profissão e a "antecipação da socialização" profissional são indissociáveis, o ingresso na instituição e todo o percurso prepara a conformidade normativa ao espírito de corpo, à disciplina e à hierarquia de autoridade, às regras de comportamento (público e privado) e ao sistema de sanções (Caforio, 2006, p. 256).

O ensino da Sociologia, nestes contextos, não se destina a formar sociólogos, mas a abordagem sociológica pode ser um contributo relevante na formação de profissionais e cidadãos preparados para lidar com situações extremas. Daqui o interesse em refletir sobre o lugar da Sociologia no ensino 
universitário militar. Começamos por apresentar um ponto da situação atual, em Portugal, seguido de um recuo histórico aos finais da década de 1950, altura em que a Sociologia passou a integrar os curricula da Academia Militar (AM). Estabelecido esse percurso, fazem-se algumas comparações internacionais que contribuirão para balancear tendências e enunciar alguns desafios.

A metodologia seguida é unicamente qualitativa, suportada pela bibliografia disponível e pela análise de documentos institucionais disponíveis em acesso aberto. A pertença institucional da autora e a experiência profissional enquanto docente da AM, embora em outras áreas das ciências socias, não deixam de mediar a compreensão do objeto.

\section{A Sociologia nas Academias Militares em Portugal}

Os Estabelecimentos de Ensino Superior Público Universitário Militar (EESPUM) têm sido objeto de profundas transformações, na sequência da adesão ao chamado Processo de Bolonha e de outras reformas conducentes sucessivamente à integração no sistema universitário nacional e internacional. A adesão a essas mudanças, incluindo a sujeição aos critérios da Agência de Avaliação e Acreditação do Ensino Superior (A3ES) confronta-se com a especificidade do ensino militar. Esta, enraíza-se em elementos vinculados à condição militar que se transporta para as instituições de ensino, organizadas em cadeias de comando, numa lógica de subordinação hierárquica e de conformidade aos valores e às normas, que no seu conjunto socializam os cadetes e antecipam as realidades institucionais nas quais se integrarão os futuros oficiais. A formação desdobra-se em múltiplas componentes, de âmbito académico, militar e comportamental (Borges, 2019) orientadas para o desempenho profissional.

A capacidade para conciliar as especificidades do ensino militar com as exigências de um sistema de ensino universitário orientado para a investigação e para a competitividade dos centros de investigação tem sido um dos principais desafios das últimas duas décadas (Carreiras, 2021).

O Instituto Universitário Militar (IUM), criado em 2015, passou a integrar os antigos institutos e escolas que formam os oficiais e sargentos dos quadros permanentes das Forças Armadas (FFAA) e da Guarda Nacional Republicana (GNR). O ensino superior militar organiza-se num sistema binário, de natureza universitária e politécnica, com o primeiro a orientar-se por formações científicas ancoradas em unidades de ensino e de investigação, e o segundo direcionado a formações vocacionais e técnicas profissionalmente orientadas. $\mathrm{Na}$ vertente universitária, o IUM confere os graus de licenciado, mestre e doutor em ciências militares. Na vertente politécnica, são atribuídos os graus de licenciado e de mestre, bem como o diploma de técnico superior profissional (Decreto-Lei n. ${ }^{\circ}$ 249/2015 de 28 de outubro do Ministério da Defesa Nacional, 2015). 
O grau de mestre constitui a habilitação mínima requerida para o ingresso nos quadros permanentes com a categoria de oficiais (Decreto-Lei n. ${ }^{\circ} 27 / 2010$, de 31 de março), formação essa ministrada na AM, na Escola Naval (EN) e na Academia da Força Aérea (AFA), instituições de ensino universitário militar que em 2015 passaram a integrar o IUM como unidades orgânicas autónomas. A caraterização que se segue (Quadro 1) apresenta os cursos que incluem Sociologia nos planos curriculares.

\section{Quadro 1. Sociologia no ensino superior universitário militar}

\begin{tabular}{|c|c|c|c|c|}
\hline Instituição & $\begin{array}{l}\text { Ciclo de } \\
\text { estudos }\end{array}$ & Cursos & \multicolumn{2}{|c|}{ Unidades Curriculares } \\
\hline \multirow{5}{*}{$\begin{array}{l}\text { Academia } \\
\text { Militar }\end{array}$} & \multirow{4}{*}{$\begin{array}{l}\text { Mestrado } \\
\text { integrado }\end{array}$} & Ciências Militares - Infantaria & \multicolumn{2}{|l|}{ Sociologia Militar } \\
\hline & & Ciências Militares - Artilharia & \multirow{2}{*}{\multicolumn{2}{|c|}{$\begin{array}{l}\text { Sociologia Militar } \\
\text { Sociologia Militar }\end{array}$}} \\
\hline & & Ciências Militares - Cavalaria & & \\
\hline & & Ciências Militares - Segurança & Sociologia Militar & $\begin{array}{l}\text { Sociologia } \\
\text { Policial }\end{array}$ \\
\hline & Mestrado & $\begin{array}{l}\text { Ciências Militares - Administração } \\
\text { da GNR }\end{array}$ & & $\begin{array}{l}\text { Sociologia } \\
\text { Policial }\end{array}$ \\
\hline \multirow[t]{5}{*}{$\begin{array}{l}\text { Academia da } \\
\text { Força Aérea }\end{array}$} & \multirow[t]{4}{*}{$\begin{array}{l}\text { Mestrado } \\
\text { integrado }\end{array}$} & $\begin{array}{l}\text { Aeronáutica Militar - Piloto } \\
\text { aviador }\end{array}$ & \multicolumn{2}{|l|}{ Sociologia Militar } \\
\hline & & $\begin{array}{l}\text { Aeronáutica Militar - Engenharia } \\
\text { Aeronáutica }\end{array}$ & \multicolumn{2}{|l|}{ Sociologia Militar } \\
\hline & & $\begin{array}{l}\text { Aeronáutica Militar - Engenharia } \\
\text { de Aeródromos }\end{array}$ & \multicolumn{2}{|l|}{ Sociologia Militar } \\
\hline & & $\begin{array}{l}\text { Aeronáutica Militar - } \\
\text { Administração Aeronáutica }\end{array}$ & \multicolumn{2}{|l|}{ Sociologia Militar } \\
\hline & Mestrado & $\begin{array}{l}\text { Mestrado em Ciências Militares } \\
\text { Aeronáutica - Engenharia } \\
\text { Aeronáutica }\end{array}$ & \multicolumn{2}{|l|}{ Sociologia Militar } \\
\hline
\end{tabular}

Fontes: AFA (2021), AM (2021) e EN (2021).

Identificam-se dez cursos em que as abordagens sociológicas concorrem para a formação académica de oficiais de várias especialidades, designadamente nas Armas combatentes, na Segurança, Engenharias e Administração. Trata-se de sociologias especializadas, de natureza aplicada ao âmbito profissional. No mestrado integrado em Ciências Militares, especialidade de Segurança, a Sociologia Militar completa-se com a Sociologia Policial, sendo esta também oferecida no mestrado (não integrado) em Administração da GNR.

Os objetivos definidos para a Sociologia Militar incidem na aplicação de conhecimentos sociológicos à interpretação/compreensão da instituição militar e processos de mudança, remetendo para a cultura, processos de socialização, lógicas de reprodução, de inclusão e de exclusão; profissionalização das forças armadas, questões de legitimidade, missões e relações com a sociedade civil; questões de género e fenómenos de pós-modernidade (AFA, 2021; AM, 2021). Também a Sociologia Policial se orienta pela aplicação das teorias e métodos sociológicos em ordem à análise do papel do Estado e da legitimidade do uso 
da força, tendo subjacente a relação entre a cidadania e a segurança; bem como convoca o conhecimento sociológico das organizações policiais para identificação e análise da atuação policial da GNR na relação com o meio envolvente (AM, 2021).

O corpo docente das duas Unidades Curriculares (UC) identificadas é constituído por professores militares, que além da formação em Ciências Militares obtiveram formação académica em universidades civis, no caso dos docentes da AM, doutoramentos em Sociologia.

Acrescente-se que os planos de estudos dos cursos acima identificados incluem outras UC das Ciências Sociais e Comportamentais, tais como Introdução às Ciências Sociais, Metodologia da Comunicação, Psicologia Militar (só na AFA) e Metodologia da Investigação. Nos planos de estudos dos mestrados integrados da Escola Naval não consta nenhuma UC de Sociologia, o Mestrado Integrado em Ciências Militares Navais, apenas contempla duas UC de Comportamento Organizacional (I e II) (EN, 2021).

\section{Recuo histórico: a entrada da Sociologia na Academia Militar}

A entrada da Sociologia na formação de oficiais ocorreu em 1959, no âmbito da reorganização da Escola do Exército, que passa a designar-se Academia Militar, cabendo-lhe a missão de formar os oficiais para os quadros permanentes do Exército e da Força Aérea. Com essa reorganização criaram-se novos cursos, alteraram-se os planos curriculares e passaram a ensinar-se novas matérias, ao encontro do que se consideravam ser os requisitos da educação intelectual necessária à "complexidade e ecletismo" das funções inerentes à profissão, dando-se especial relevo às capacidades técnico-científicas aplicadas à guerra e ao desenvolvimento de "uma bem cuidada cultura geral e humanística" de que um oficial de carreira necessita por "ter permanentemente de enfrentar, como instrutor, como educador e como chefe, melindrosos problemas humanos" (Decreto-Lei n. 42151 de 12 de fevereiro da Presidência do Conselho e Ministério do Exército, 1959).

A Sociologia está entre as novas matérias a ensinar na renovada escola de oficiais. Sociologia Geral é a 20 a de um rol de 54 cadeiras oferecidas com diferentes combinações nos dez cursos existentes: Infantaria, Artilharia, Cavalaria, Transmissões; Engenharia Militar, e Engenharia Militar nas especialidades Eletrotécnica, Mecânica; Administração Militar e Engenharia Aeronáutica Militar (Decreto-Lei $n^{\circ}$ 42151, de 12 de fevereiro de 1959). A disciplina não fazia parte do tronco comum de formação, estava reservada aos cursos de Engenharia, cujo plano de estudos, no que respeita à componente académica, passou a ser semelhante à que vigorava no Instituto Superior Técnico (IST), onde os estudantes da AM concluíam os últimos anos da sua formação (já como oficiais). 
Por sua vez, a inserção da Sociologia nos planos de estudos dos cursos de Engenharia, na Faculdade de Ciências e no IST, data de 1955, época em que Leite Pinto (fundador da Junta Nacional de Investigação de Investigação Científica e Tecnológica) ocupava a pasta de Ministro da Educação Nacional. O fundamento para esta inclusão advém de uma certa abertura à modernização e às influências externas, de onde emanam críticas à especialização de pendor tecnicista, um risco que o preâmbulo do Decreto-Lei 40378, de 14 novembro de 1955, trata de reportar:

Os Estados Unidos formaram técnicos que estão longe de ser homens educados; são capazes de realizar a sua tarefa restrita, e de a realizar convenientemente; mas, ignorando a literatura (chave do comportamento humano), a história, a economia, a geografia, a sociologia, as matemáticas, as línguas, etc., não podem relacionar a sua especialidade com o ambiente geral.

Depois de convocados exemplos do debate intelectual europeu e extraeuropeu a contrariar a excessiva especialização precoce dos engenheiros, o tex to conclui: "É em estrito acatamento dessa clara lição que nos novos planos se alarga a representação das disciplinas de Matemática e de Física" e "se inscreve pela primeira vez a disciplina de Sociologia Geral (Questões morais e sociais relacionadas com a técnica)" (Decreto-Lei n. 40378 de 14 novembro do Ministério da Educação Nacional - Direcção-Geral do Ensino Superior e das Belas-Artes, 1955). Não deixa de ser curioso o complemento que entre parenteses se acrescenta à designação da disciplina, mas que aparentemente não se transpôs para a disciplina equivalente na AM (a julgar pelo plano de estudos publicado no Decreto-Lei $n^{\circ} 42151$ de 12 de fevereiro da Presidência do Conselho e Ministério do Exército, 1959).

Esta incursão pela reforma dos cursos de Engenharia (e seu reflexo na AM) torna mais compreensível que o regime autoritário tenha tolerado a entrada da Sociologia numa escola de oficiais, num contexto de gradual contestação social, pouco antes do início da Guerra Colonial e sabendo-se da suspeição que esta área do saber despertava, a ponto de Salazar a ter considerado "um socialismo disfarçado" (Nunes, 1988, p. 37).

Mas, se o efeito da reforma da Engenharia é ineludível, a abertura às Ciências Socias e Humanas também se encontra em outras evidências. A Introdução às Ciências Sociais consta no plano de estudos de os cursos (com exceção das Engenharias, que como se disse tinham Sociologia), bem como a Psicologia, Pedagogia e Arte de Comandar, disciplina do tronco comum. Outra evidência, relacionada com a anterior, e muito significativa até no plano simbólico, é a contratação pela AM de um dos pioneiros da Sociologia portuguesa, Adérito Sedas Nunes, e isto depois de lhe ter sido bloqueado o ingresso no 
Instituto Superior de Ciências Sociais e Política Ultramarina (ISCSPU, atualmente Instituto Superior de Ciências Sociais e Políticas, ISCSP). Uma informação negativa da polícia política foi o que travou a contratação pelo ISCSPU, informação de conteúdo semelhante se repetiu quanto ao ingresso na AM, mas não foi impeditiva, porque como explica o próprio Sedas Nunes (1988, p. 42), o então Comandante, General Buceta Martins "pôde passar sobre ela". As disciplinas à responsabilidade de Sedas Nunes (Sociologia Geral e Introdução às Ciências Sociais) representavam para os cadetes-alunos "uma janela sobre o mundo" (Nunes, 1988, p.42).

No IST, A Sociologia Geral acabou por ser excluída da formação dos engenheiros em 1970, mas na AM manteve-se até mais tarde. Entretanto, reforçou-se a componente mais aplicada ao campo profissional, com a Sociologia Militar e a Sociologia Policial a fazerem parte do plano de estudos identificados no ponto anterior.

\section{Dos cenários internacionais: a chegada da Sociologia às Academias Militares}

Não é propriamente um tema sobre o qual exista produção abundante, mas a pesquisa bibliográfica permite algumas comparações internacionais quanto ao reconhecimento da Sociologia nas Academias Militares, trabalho que em certa medida nos transporta duplamente para a história da Sociologia contemporânea e para a relação entre campo militar e campo académico. O exercício comparativo deverá ser apreciado com cautela, condicionado que está pelos dados disponíveis e pela grande diversidade de modelos de formação prevalecente no ensino superior militar. Também a própria heterogeneidade cultural entre as academias tem sido assinalada, por exemplo, a obediência e conformidade normativa à disciplina pode ser relativamente mais ou menos importante (Soeters e Recht, 1998).

Historicamente, a formação dos oficiais tem forte componente das áreas técnico-científicas e das matemáticas, dando-se por adquirido que esses seriam os conhecimentos mais úteis à decisão do comandante. Nestas formações, expressamente orientadas para o desempenho profissional e em que os exemplos práticos e o respeito pela doutrina prevalecem, as abordagens teóricas de questões como o poder, a disciplina, a obediência e as relações socias são pouco atraentes para quem as vê como "elementos naturais e necessários da profissão" (Danielsson e Weibull, 2008, p. 93). Assim, a Sociologia, pela sua conotação crítica e politizada, só gradualmente foi vencendo as resistências do universo militar, um pouco à medida que se descobria a utilidade dela face a necessidades concretas da in stituição militar, nos vários contex tos de ação. Esta dimensão aplicada da sociologia, virada para a solução de problema práticos, que o campo militar tanto aprecia, confronta-se com uma certa desvalorização 
desta sociologia "dos práticos", um dilema que como se sabe tem gerado um amplo debate na comunidade sociológica. A combinação dos dois registos, o científico e o aplicado ao campo militar, em que o acesso comporta requisitos específicos, traz à colação uma espécie de oposição de dois ideais de sociólogos: "o insider integrado no campo militar e desacreditado no campo da sociologia; o ousider, reconhecido no campo da sociologia e ausente no terreno militar", circunstância que concorre para o isolamento da sociologia militar (Martin e Pajon, 2015, p. 25), mas com variações no historial de cada país.

Foi durante a II Guerra, nos EUA, que o campo militar começou a reconhecer mais regularmente a utilidade do conhecimento sociológico, em assuntos determinantes para a estrutura militar, como o recrutamento, a motivação para o combate e a moral das tropas, o que deu origem a um extenso programa de pesquisas de que se destacam os trabalhos dirigidos por Samuel Stouffer et al., celebrizados na obra The American Solider (1949).

Depois, num mundo a refazer-se da Guerra Mundial e na iminência da guerra fria, o papel da Sociologia e as demais Ciências Sociais equaciona-se em outros moldes. Destacamos o apoio da UNESCO à fundação da Associação Internacional de Sociologia (ISA), em 1948, com o objetivo de promover a investigação em Ciências Sociais ao nível mundial, na convicção de que o conhecimento das realidades sociais beneficiaria a humanidade e seria crucial para o estabelecimento de uma ordem mundial pacífica (Platt, 1998).

A configuração de um subcampo de investigação dedicado à análise social da instituição militar nasce nos EUA, primeiro em torno do Inter-University Seminary on Armed Forces and Society (IUS), fundado em 1960, e, pouco depois (1964), com a criação do Research Committee (RC01) da ISA Armed Forces and Society (Armed Forces and Conflit Resolution, na nomenclatura atual). Morris Janowitz esteve na origem de ambas as iniciativas e foi o primeiro coordenador das estruturas. Cada uma a seu modo, as duas contribuíram para estruturar o campo: agregaram uma comunidade de interesses em torno da análise da instituição militar, elegeram os objetos de estudo, as problemáticas e o suporte teórico metodológico de que a Sociologia Militar se tem vindo a reclamar. A revista Armed Forces and Society, fundada pelo IUS, e as conferências das duas estruturas são especialmente ilustrativas das temáticas e das abordagens que decisivamente influenciaram a estruturação de um subcampo da Sociologia.

Pelo lado dos investigadores europeus, surge em 1986 um outro espaço de reflexão, o European Research on Military and Society (ERGOMAS), criado em reação ao excessivo controlo que os EUA tinham nas organizações internacionais, o que fazia com que as questões e problemas europeus ficassem subalternizadas (ERGOMAS, 1986). Hoje a divisão parece ter dado lugar à colaboração. 
Com raras exceções, a inclusão da Sociologia na formação dos oficiais é contemporânea do contexto acima descrito, que é também um período de reformas nas estruturas curriculares, reorientadas de conteúdos mais técnicos, para horizontes de formação mais académicos e mais alargados, movimento este favorável às Ciências Sociais. Nos EUA, a influência de Janowitz é notória neste movimento, que se expande até à Europa e envolve investigadores como Van Doorn, com grande influência na institucionalização da Sociologia Militar na Holanda. A estes dois "pais fundadores" da Sociologia Militar (Moelker e Soeters, 2008, p. 36) juntam-se, na Universidade de Chicago, alguns jovens investigadores europeus, como Boëne e Abrahammson que também influenciaram a Sociologia Militar, respetivamente em França e na Suécia. Ainda sob a influência intelectual de Janowitz, um grupo de jovens sociólogos (David Segal, Mady Segal, James Burk e Brenda Moore) formam-se na Universidade de Chicago e contribuem para a institucionalização da Sociologia Militar (Segal e Ender, 2008).

No resumo que Segal et al (1990) apresentam, são tipicamente quatro os problemas a solucionar para incluir a Sociologia nas escolas militares. Implica estabelecer a legitimidade da Sociologia, quando as Ciências SócioComportamentais não fazem parte do currículo ou quando se considera que outras disciplinas já existentes cobrem as matérias que se trata de introduzir. O sucesso desse empreendimento requer adaptação da nova disciplina às normas e valores da instituição em que vai ser integrada, bem como a aproximação às expectativas dos estudantes sobre a articulação entre as componentes teóricas e práticas da aprendizagem. Finalmente, o problema do recrutamento e ou formação de um corpo docente preferencialmente familiarizado com a instituição militar, para potenciar a relevância da aprendizagem para a prática profissional (M. Segal et al, 1990)

A inserção de um programa de Sociologia no universo das Academias Militares implica ultrapassar resistências e aproveitar as oportunidades criadas em contextos de mudança, não sendo irrelevante o papel que o prestígio de personalidades influentes pode exercer. $\mathrm{Na}$ figura inscrevem-se os marcos temporais do início desses processos em algumas academias.

Fig. 2. O início da Sociologia nas Academias Militares

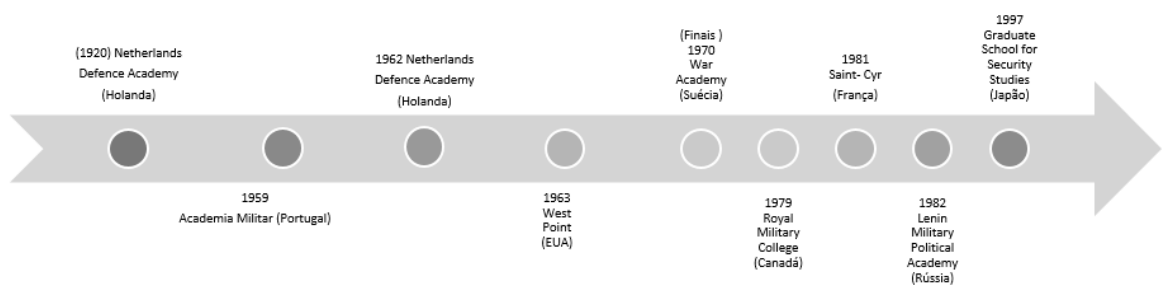


$\mathrm{Na}$ Holanda, o ensino da Sociologia como ciência formalmente inserida nos planos de estudos militares começa no início da década de 1960, sob influência de Van Doorn. Mas é interessante notar que já em 1920 as questões de Sociologia (assim como de Psicologia e Pedagogia) eram mobilizadas para as aprendizagens informais direcionadas para desenvolver nos oficiais as competências sociais inerentes à profissão e à condição social. Depois dos anos 60, o desenvolvimento da Sociologia Militar percorreu várias fases: prosperou com o facto da profissão dos oficiais se ter tornado algo "híbrida", exigindo competências miliares e civis mobilizáveis para os novos cenários das operações de apoio à paz; adaptou-se à filosofia problem-based learning, em cursos multidisciplinares como Contemporary Conflict Resolution, em que, por exemplo, os alunos estudam os problemas com que se confrontam os soldados em missão e investigam as possibilidades e condicionantes da intervenção. Apesar de reconhecida, como concluem Moelker e Soeters (2008), a Sociologia Militar tem de sistematicamente provar o seu valor, ora perante o descrédito de alguns militares, ora perante o desinteresse que a comunidade académica dedica às questões militares, reminiscências do antimilitarismo dos anos 60. "A sociologia militar tem de provar ser verdadeiramente científica para satisfazer os académicos e, por outro lado, ser verdadeiramente pragmática e útil para satisfazer os militares" (Moelker e Soeters, 2008, p. 46).

A Academia Militar em Portugal, como se viu no ponto anterior, introduz no plano de estudo dos Cursos de Engenharia a Sociologia Geral, ainda antes da institucionalização universitária dessa ciência. Foi na sequência da reforma modernizadora a que foram sujeitos todos os cursos de Engenharia, mas enquanto os outros cursos suprimiram a Sociologia na reforma seguinte, na Academia Militar manteve-se. O prestígio que o professor Sedas Nunes angariava junto do Comandante não será alheio a esse desenvolvimento. A Sociologia Militar e a Sociologia Policial (esta para os cursos destinados aos futuros oficiais da GNR) surgiram mais tarde e constituem presentemente programas de aprendizagem bem definidos, sob a responsabilidade de professores militares, com Doutoramentos em Sociologia e ligações ao meio académico exterior.

Em West Point, o primeiro curso de Introdução à Sociologia inicia-se em 1963, e dois anos depois surge a Sociologia Militar. No início dos anos 70, com o acentuar da tensão rácica, quer no campo militar, quer na sociedade americana, acrescenta-se uma Sociologia das Minorias. Entretanto, os efeitos da guerra do Vietname e a onda crítica que os jovens e intelectuais protagonizam mais profundamente, refletem-se num afastamento entre o campo militar e o campo académico, com efeitos para o lugar da Sociologia, temporariamente a perder terreno, com a suspensão da Sociologia das Minorias e da Sociologia Militar, que mais tarde viriam a ser retomadas. Uma mudança mais radical surge em 1984, com o perfil de ensino a transitar do clássico modelo da Engenharia 
para Majors com opcionais no âmbito das Ciências Comportamentais, com uma forte componente da Sociologia (Segal et al, 1990).

A oscilação das disciplinas oferecidas na Academia de West Point tem sido grande e acompanha-se da redução do peso da Sociologia (e de outras ciências sociais) para acomodar matérias emergentes, por exemplo as línguas estrangeiras, entendidas como competências cruciais no contexto da luta conta o terrorismo. Além dos Majors em Sociologia, existem optativas que estudantes de outros cursos podem frequentar, mas dependendo das escolhas dos alunos só cerca de 2 a $3 \%$ dos cadetes obtém aproximações às abordagens sociológicas. Quanto aos Majors, seguem os requisitos estabelecidos pela American Sociological A ssociation (ASA), e a ligação à comunidade académica é fortalecida pelas qualificações que o corpo docente (maioritariamente militar) obtém em universidades civis prestigiadas, sobretudo as que mais se têm distinguido na Sociologia Militar: a Universidade de Maryland, com os trabalhos de Mady Segal e David Segal (ambos simultaneamente ligados à Academia Militar de West Point); a Universidade de Chicago, com a produção de Morris Janowitz; e a Universidade de Northwestern, com os contributos de Charles Moskos (Ender et al, 2008).

No caso da Suécia, Danielsson e Weibull (2008) consideram que a dominância de aprendizagens orientadas para a prática militar contribuiu para manter a Sociologia afastada da formação de oficiais, ainda que no país se encontrem abordagens de Sociologia Militar desde meados do século XX, destacando-se os trabalhos de Bengt Abrahamsson. A par de conteúdos da Sociologia dispersos em vários cursos, por volta de finais de 1970 a Sociologia torna-se matéria optativa na Academia Militar Sueca. Posteriormente, já no atual National Defence College (junção da War Academy e do Defence College), as teorias sociológicas passaram a integrar os cursos de liderança e outros cursos temáticos, dedicados a questões comportamentais, processos de decisão, valores e atitudes, entre outros. $\mathrm{Na}$ mais recente reestruturação dos cursos de oficiais, segundo os autores citados, a procura de contributos da Sociologia progrediu, beneficiando da viragem mais académica e, sobretudo, pelo trabalho educacional necessário acerca dos papéis profissionais decorrentes do envolvimento das Forças Armadas nos cenários internacionais (Danielsson e Weibull, 2008).

Para a Academia Militar francesa, as reestruturações curriculares de 1982 (acréscimo da duração do curso e reforço da componente académica) e de 2000 (introdução do ciclo de Mestrado) constituíram oportunidades para o desenvolvimento da Sociologia na escola de Saint-Cyr, um desenvolvimento comparativamente tardio, face ao panorama internacional, sobretudo se pensarmos na forte tradição da Sociologia francesa. "Um frágil sucesso", é como Bernard Boëne (2008, p. 31) qualifica a história da Sociologia da Academia Militar francesa: foi necessário demonstrar como a Sociologia contribuiria para as capacidades militares em termos de reflexividade e ação, numa época em que 
a interoperabilidade cultural se exige e a dimensão internacional se reforçou; contornaram-se dissidências em relação a outras áreas do saber e evitaram-se controvérsias quanto a metodologias de ensino. Os novos currículos permitem que os cadetes optem por fazer um mestrado em Sociologia, ou que escolham opções que os familiarizam com a análise de questões centrais às ciências sociais, mas em sentido contrário, a Sociologia deixou de ser uma disciplina transversal, perdendo o seu papel pivot que lhe permitiu ser "uma fonte rara de homogeneidade num corpo de oficiais cada vez mais diversificado" (Bernard Boëne, 2008, p. 31). Apesar do sucesso que se foi conquistando, Boëne (2008) dá conta de um caminho algo turbulento, em que a Sociologia tem sistematicamente de conquistar o seu lugar.

O exposto ilustrou algumas breves histórias da Sociologia no ensino de oficiais, em que encontramos uma diversidade de situações, mas também algumas semelhanças. Usaremos agora o ensaio de Segal e Ender (2008), baseado no estudo de Academias Militares de nove países, para tipificar tendências, que segundo os autores são seis: o estigma, a canibalização, a cooptação, a liderança carismática, a mudança social radical e a revitalização.

A necessidade de ultrapassar estigmas é um exercício que certas áreas do conhecimento conhecem bem e a Sociologia em particular. No meio militar, tudo se conjuga para que esta ciência seja vista como suspeita, pois a visão crítica das instituições faz parte do métier e a instituição militar "é vista por muitos sociólogos como a burocracia por excelência que inibe a capacidade humana e mantém a desigualdade social em nome do Estado" (Segal e Ender, 2008 , p. 9). A proximidade de muitos sociólogos aos movimentos libertários e antimilitaristas dos anos 60 concorre para alimentar suspeitas, dificuldade que as experiências das academias holandesa e francesa tiveram de ultrapassar. Mas também da parte da comunidade académica emergiram estigmas, casos há em que o estudo das questões militares chegou a suscitar um certo "desdém" (Suécia, por exemplo); noutros casos acentuou-se a dimensão crítica da aplicação da Sociologia ao campo militar, vendo nisso uma "engenharia social", por exemplo instrumento pró-Apartheid na África do Sul (Heinecken e Visser, 2008; Segal e Ender, 2008). A este propósito importa dizer que "nos anos 70 e 80 existia um controlo estrito dos media e pesados elementos de censura e intimidação para aqueles que se atrevessem a 'opor-se' ou a expor assuntos militares" (Heinecken e Visser, 2008, p. 145).

Nas dinâmicas dos arranjos curriculares, algumas academias canibalizaram disciplinas de Sociologia para integrar os mesmos conteúdos em outras disciplinas do currículo. Segal e Ender (2008) ilustram a tendência com exemplos de que selecionamos os seguintes: em West Point, matérias como comportamento organizacional, habitualmente inseridas nos programas de sociologia, transitam para os cursos de psicologia ou de gestão; na África do 
Sul, a Sociologia surge diluída dentro de outras disciplinas, por exemplo, em Psicologia Industrial, Gestão Pública ou História Militar.

$\mathrm{Na}$ ideia de cooptação, próxima da canibalização, os autores incluem as situações em que conhecimentos sociológicos específicos são integrados em módulos de outros cursos. Dos exemplos constam a integração de conceitos como coesão, desviância ou atitudes nos estudos de Liderança em West Point; a inclusão de questões de género e etnicidade em programas de Psicologia ou de Gestão (por vezes sem visão crítica), que Pinch e Ouellet (2008) encontram no Canadá; ainda em West Point, ocorrem workshops, organizados pelos cadetes seniores, em que são chamados temas centrais da Sociologia, como a socialização, o assédio sexual, questões de género e outras temáticas, mas cuja abordagem é feita sem conexão aos seus programas (Segal e Ender, 2008). Na África do Sul, o colapso do Apartheid e as alterações estratégicas do contexto de Defesa e Segurança propiciaram reorientações na formação dos oficiais, num sentido mais interdisciplinar para o que as Ciências Sociais foram chamadas a contribuir, com significativas alterações de conteúdos; as abordagens sociológicas são amplamente mobilizadas, nos vários cursos e por várias disciplinas, sem que existam propriamente disciplinas de Sociologia (Heinecken e Visser, 2008).

Nas academias de alguns países, o lugar que a Sociologia veio a ocupar é indissociável do esforço individual e do prestígio que algumas pessoas conseguiram mobilizar para vencer resistências: é o caso Charles Cotton e Frank Pinch no Canadá, Bernard Böene em França, Bengt Abrahamsson na Suécia, e Jacques Van Doorn na Holanda (Segal e Ender, 2008). Em West Point a influência de autores como Mady Segal, David Segal, Morris Janowitz e Charles Moskos é inquestionável, pela produção científica e muito especialmente por, nas universidades civis em que lecionam, terem formado a maior parte dos professores militares que ensinam Sociologia. É neste sentido que Segal e Ender (2008) mencionam a relevância da liderança carismática que, como se viu, também se refletiu em Portugal nos primórdios da Sociologia na Academia Militar.

O fim da conscrição, a maior heterogeneidade da origem social dos alunos das academias, a abertura das Forças Armadas às mulheres, a internacionalização e emergência das novas missões de apoio à paz, são algumas das mudanças radicais com que o campo militar se tem confrontado. Apesar da formação de oficiais ser, nos aspetos centrais, sustentada em modelos estáveis e duradouros, as mudanças tiveram acolhimento nas estruturas curriculares, redirecionando os planos de estudos para abordagens mais académicas, em geral beneficiando as ciências sociais. Além das problemáticas da Sociologia Militar, os temas que mais convocam as abordagens sociológicas são a família, criminologia, interculturalidade, etnicidade, classe, género e sexualidade (Segal e Ender, 2008). 
Para terminar, a revitalização dos programas de Sociologia parece ser, das seis tendências, a mais partilhada. Perante as mudanças de contexto, desenvolveram-se novos currículos em que a Sociologia acrescenta valor à formação dos oficiais, são exemplo as abordagens de temas como a sociologia da guerra, a relação entre Forças Armadas e Sociedade, a profissão militar, a composição sociodemográfica das forças, a diversidade cultural, o género, a sexualidade, e outros tópicos, tudo se conjugando para um impacto positivo na legitimidade da investigação e do ensino da Sociologia em contexto militar (Segal e Ender, 2008).

\section{Notas conclusivas}

Em Portugal, em momentos diferentes, podemos igualmente encontrar algumas das tendências que Segal et al (2008) identificaram na história e atualidade da Sociologia nas Academias Militares. Do lado das personalidades influentes, o papel de Sedas Nunes parece ter sido decisivo para legitimar a entrada da Sociologia na formação de oficiais, no início da década de 1960, ilustrando o quanto académicos e militares prestigiados podem contribuir para promover a intercompreensão entre o campo académico e o campo militar. Expressamente no âmbito da Sociologia Militar, os trabalhos de Maria Carrilho e Helena Carreiras devem ser assinalados pelos contributos que trouxeram à delimitação desse subcampo da Sociologia. O facto de Helena Carreiras dirigir o Instituto da Defesa Nacional, desde julho de 2019, pode também ser visto como sinal de aproximação entre os dois campos.

A cooptação de conceitos e de metodologias, de que também encontramos exemplos nas Academias Militares é, na verdade, transversal ao campo académico e mereceria, por isso, uma reflexão mais alargada. Se há temáticas de teor marcadamente interdisciplinar, em que o cruzamento de perspetivas é enriquecedor e mesmo se impõe, também ocorrem situações em que conceitos, métodos e técnicas são extraídas da Sociologia e agregados em avulso a outros contextos, numa espécie de sedutor prêt-à-porter.

Com operações militares cada vez mais complexas a desenvolverem-se em meios urbanos, com o que isso requer do ponto de vista do contacto com as populações, no trabalho conjunto com forças internacionais e com outros atores, tudo sob forte escrutínio público, a Sociologia (e outras Ciências Sociais) foi conquistando terreno e legitimidade na formação de oficiais. A recomposição curricular foi adaptada e a adoção dos critérios definidos pela A3ES contribuiu para reforçar a componente científica, quer no ensino, quer na investigação, o que em termos genéricos foi favorável às Ciências Sociais.

Mas, apesar destas tendências favoráveis, há sempre margens de incerteza que importa acompanhar para melhor enfrentar novos desafios. Por exemplo, em resultado da avaliação da A3ES, os Mestrados Integrados em Ciências 
Militares, na especialidade de Administração Militar e Administração da GNR, passaram a dois ciclos (Licenciatura e Mestrado), o que implicou reconfigurações curriculares, em prejuízo da Sociologia Militar. Caminhou-se, desta vez, numa espécie de contracorrente face às tendências internacionais, em que os processos de mudança têm contribuído para revitalizar a Sociologia Militar.

Em suma, refletir sobre o ensino da Sociologia na formação daquelas e daquelas que, no futuro, serão profissionais das Forças de Segurança e das Forças Armadas é um desafio de grande atualidade e relevância, um balanço que ganhará equilíbrio se nele participarem as várias vozes, do campo académico, do campo profissional e do campo dos decisores. É o que nos propomos fazer no âmbito da Secção Segurança, Defesa e Forças Armadas, de que fazem parte docentes, investigadores e outros profissionais ligados à área. Procuremos estimular a cooperação entre o "interior" e o "exterior" dos sistemas da Segurança e da Defesa, pois, nas palavras de Boëne (2007, p. 106), "se o quadro é diferente, as necessidades são as mesmas".

\section{Referências bibliográficas}

AFA - Academia da Força Aérea [em linha]. Sintra: Academia da Força Aérea. 2021 [consult. 2 mar. 2021]. Disponível em: https://www.academiafa.edu.pt/p-493-mestrado.

AM - Academia Militar [em linha]. Lisboa: Academia Militar. 2021 [consult. 2 mar. 2021]. Disponível em: https://academiamilitar.pt/ensino/mestrados-integrados.html.

BOËNE, Bernard - Sécurité et Défense en France et en Europe. Nação e Defesa. Lisboa. ISSN: 0870-757X. $116: 3$ (2007), p. 81-106.

BOËNE, Bernard - Teaching Sociology at Saint-Cyr, 1983-2004 and beyond. A personal account. Armed Forces \& Society. San Marcos, TX. ISSN : 0095327X. 35: 1 (2008), p. 16-35.

BORGES, João Vieira - A especificidade do ensino superior militar. Revista Militar [em linha]. 2608 (2019), p. 611-635 [consult. 17 mar. 2021]. Disponível em: https://www.revistamilitar. pt/artigo/1435. ISSN : 0873-7630.

CAFORIO, Giuseppe - Military Officer Education. In CAFORIO, Giuseppe (ed.) - Handbook of the sociology of the military. New York: Springer, 2006. ISBN: 978-3-319-71600-8. p. 255-278.

CARREIRAS, Helena - Bridging two worlds: the knowledge-policy linkage in the study of the Portuguese Armed Forces. In BEN-ARI, Eyal; CARREIRAS, Helena; CASTRO, Celso (eds.) - The Impact of Social Research on the Military: Reflections and Critiques. London: Routledge, (2021) (no prelo).

DAN IELSSON, Erna; WEIBULL, Alise - Sociology at Military Academies: The Swedish Case. Armed Forces \& Society. San Marcos, TX. ISSN: 0095327X. 35: 1 (2008), p. 91-105.

Decreto-Lei n. 40378 de 14 novembro de 1955 do Ministério da Educação Nacional Direcção-Geral do Ensino Superior e das Belas-Artes [em linha]. Diário do Governo: I Série, n. ${ }^{\circ}$ 248/1955 [consult. 17 mar. 2021]. Disponível em: https://dre.pt/web/guest/pesquisa/-/search/248067/details/maximized?filterEnd=1955-12-31\& filterStart=1955-01$01 \& \mathrm{q}=1955 \&$ perPage $=100 \& \mathrm{fqs}=1955$.

Decreto-Lei n. 42151 de 12 de fevereiro de 1959 da Presidência do Conselho e Ministério do Exército [em linha]. Diário do Governo: I Série, n. ${ }^{\circ} 36 / 1959$ [consult. 17 mar. 2021]. Disponível em: https://dre.pt/web/guest/pesquisa/-/search/590727/details/ 
maximized?filterEnd=1959-12-31\& sort=when Searchable\& filter St a r $\mathrm{t}=1959-01-$ $01 \& \mathrm{q}=1959 \&$ sortOrder=ASC \& print_preview $=$ print-preview $\&$ fqs $=1959 \&$ perPage $=100 \& \mathrm{dr}$ $\mathrm{eId}=60702$.

Decreto-Lei n. ${ }^{\circ}$ 249/2015 de 28 de outubro de 2015 do Ministério da Defesa Nacional [em linha]. Diário da República: I Série, n. ${ }^{\circ}$ 211/2015 [consult. 17 mar. 2021]. Disponível em: https:// dre.pt/home/-/dre/70832992/details/maximized.

EN - Escola Naval [em linha]. Lisboa: Escola Naval. 2021 [consult. 2 mar. 2021]. Disponível em: https://escolanaval.marinha.pt/pt/ensino_web/mestradosintegrados/Paginas/marinha.aspx.

EN DER, Morten G.; KELTY, Ryan; SMITH, Irving - Sociology at West Point. Armed Forces \& Society. San Marcos, TX. ISSN : 0095327X. 35: 1 (2008), p. 49-70.

ERGOMAS - European Research on Military and Society - 1986-1988: Founding ERGOMAS. Founding Workshop in Lavandou [em linha]. October 31 - November 2, 1986 [consult. 5 jun. 2021]. Disponível em: https://www.ergomas.ch/images/stories/documents/1986-1988. pdf.

HEINECKEN, Lindy; VISSER, Deon - Officer Education at the South African Military Academy Social Science but No Sociology?. A rmed Forces \& Society. San Marcos, TX. ISSN : 0095327X. 35: 1 (2008), p. 145-161.

MARTIN, Claude; PAJON, Christophe - La sociologie militaire par les personnels de la défense : une sociologie d'insiders? Les Champs de Mars. Paris. ISSN: 1253-1871. 27: 2 (2015), p. $23-30$.

MOELKER, René; SOETERS, Joseph - Van Doorn and beyond. From teaching sociology to interdisciplinary, problem-based learning in dutch officer training. Armed Forces \& Society. San Marcos, TX. ISSN: 0095327X. 35: 1 (2008), p. 36-48.

NUNES, A. Sedas - H istórias, uma história e a História: sobre as origens das modernas Ciências Sociais em Portugal. Análise Social. Lisboa. ISSN: 00032573. 24: 100 (1988), p. 11-55.

PINCH, Franklin C.; OUELLET, Eric-Sociology in the Canadian Military Academy Curriculum. A rmed Forces \& Society. San Marcos, TX. ISSN: 0095327X. 35: 1 (2008), p. 71-90.

PLATT, Jennifer - History of ISA 1948-1997 [em linha]. Québec: International Sociological Association, 1998 [consult. 5 jun. 2021]. Disponível em: https://www.isa-sociology.org/ uploads/files/histoy-of-isa-1948-1997.pdf. ISBN : 84-605-7747-3.

SEGAL, David; ENDER, Morten G. - Sociology in Military Officer Education. Armed Forces \& Society. San Marcos, TX. ISSN: 0095327X. 35: 1 (2008), p. 3-18.

SEGAL, Mady; SEGAL, David; WATTENDORF, John M. - The sociology program in a professional school setting: the United States military academy. Teaching Sociology. Washington, DC. ISSN : 0092055X. 18: 2 (1990), p. 156-163.

SOETERS, J.; RECHT, R. - Culture and discipline in military academies: an international comparison. Journal of Political and Military Sociology. Gainesville, FL ISSN: 00472697. 26: 2 (1998), p. 169-189.

STOUFFER, Samuel A.; SUCHMAN, Edward A.; DEVINNEY, Leland C.; STAR, Shirley A.; WILliAMS JR., Robin M. - The A merican Soldier. Studies in social psychology in World War II (vols. 1-2) [em linha]. Princeton: Princeton University Press, 1949 [consult. 2 jun. 2021]. Disponível em: https://archive.org/details/in.ernet.dli.2015.130630/mode/2up.

- Receção: 16.06.2021

- Aprovação: 26.10.2021 